\title{
Intestinal microbiota and chronic constipation
}

\author{
Ying Zhao ${ }^{1}$ and Yan-Bo Yu 2* $^{*}$
}

\begin{abstract}
Chronic constipation is a prevalent, burdensome gastrointestinal disorder whose aetiology and pathophysiology remains poorly understood and is most likely multifactorial. Differences in the composition of the intestinal microbiota have been demonstrated when constipated patients and healthy controls have been compared. Growing evidence indicates that alterations of intestinal microbiota may contribute to constipation and constipation-related symptoms. The intestinal microbiota is a collection of microorganisms that live within the gastrointestinal tract, and perform many important health-promoting functions. The intestinal microbiota aids in the breakdown of food products into absorbable nutrients, stimulates the host immune system, prevents growth of pathogenic bacteria and produces a great variety of biologically important compounds. In this review, we will summarize the current evidence supporting roles of the intestinal microbiota in the pathogenesis and management of chronic constipation. The discussion will shed light on the novel mechanisms of intestinal microbiota and gut function interactions, which is invaluable in ultimately developing new therapeutic tools for the treatment of chronic constipation.
\end{abstract}

Keywords: Intestinal microbiota, Chronic constipation, Gut motility, Probiotics

Chronic constipation is a symptom-based gastrointestinal disorder characterized by difficult or infrequent passage of stool, hardness of stool, and/or a feeling of incomplete evacuation. It can result in some discomfort such as abdominal distension, abdominal pain, headache, dizziness and poor appetite. Constipation has an estimated prevalence reaching up to $20 \%$ in some populations, and this condition affects patients of all ages and gender and severely impacts on their quality of life (Bharucha 2007). The aetiology and pathophysiology of chronic constipation remains poorly understood and is most likely multifactorial. Furthermore, the clinical management of chronic constipation remains challenging. Growing evidence indicates that alterations of intestinal microbiota may contribute to constipation and constipation-related symptoms, which attracts considerable interest among gastrointestinal researchers in recent years.

The intestinal microbiota is a collection of microorganisms that live within the gastrointestinal tract, with concentrations of up to $10^{11}-10^{12}$ cells/g luminal contents.

\footnotetext{
*Correspondence: yuyanbo2000@126.com

2 Department of Gastroenterology, Qilu Hospital, Shandong University, Jinan 250012, People's Republic of China

Full list of author information is available at the end of the article
}

It is recognized that the number of bacteria within the gut is nearly 10 times that of the cells in the human body, including up to 1000 different bacterial species (Blaser et al. 2013). The microorganisms have a symbiotic relationship with their host, and perform many important health-promoting functions. The intestinal microbiota aids in the breakdown of food products into absorbable nutrients, stimulates the host immune system, prevents growth of pathogenic bacteria and produces a great variety of biologically important compounds, such as short-chain fatty acids (SCFAs) and neuro-modulatory substances. Multiples studies have revealed disturbances in the composition and stability of the gut microbiota in constipated patients compared with healthy controls. In this review, we will summarize the current evidence supporting roles of the intestinal microbiota in the pathogenesis and management of chronic constipation.

\section{Possible alterations of intestinal microbiota in chronic constipation}

Using standard cultural and/or molecular approaches, quantitative difference among intestinal microbiota species has been extensively studied. Alterations of intestinal 
microbiota in patients with chronic constipation can be characterized by a relative decrease in obligate bacteria (e.g. Lactobacillus, Bifidobacterium, and Bacteroides spp.) and a parallel increase of potentially pathogenic microorganisms (e.g. Pseudomonas aeruginosa and Campylobacter jejuni) (Gerritsen et al. 2011; Kirgizov et al. 2001). These alterations may influence intestinal motility and secretory functions by changing the amount of available physiologically active substances and the metabolic environment of the gut. Khalif et al. reported that the levels of Bifidobacteria and Lactobacillus were significantly decreased in adult patients with constipation (Khalif et al. 2005). Patients with constipation predominant-irritable bowel syndrome (IBS-C) exhibited a significant increase of Bacteroides sp. and Enterobacteriaceae (Simren et al. 2013). Further, the concentrations of Bifidobacteria, Clostridium leptum and Faecalibacterium prausnitzii were decreased in these patients with IBS-C (Nourrisson et al. 2014). Meanwhile, one pediatric study indicated that Clostridia and Bifidobacteria were significantly increased in feces of constipated children. Besides, the clostridium species isolated from constipated children were different from those from healthy controls (Zoppi et al. 1998). Using 16S rRNA gene pyrosequencing method, Zhu et al. observed significantly decreased abundance in Prevotella and increased representation in several genera of Firmicutes in constipated patients compared with controls (Zhu et al. 2014). Butyrate-producing genera, such as Coprococcus, Roseburia and Faecalibacterium, tended to be increased in constipated patients (Pryde et al. 2002; Sokol et al. 2008). These studies indicated that constipation could be a consequence of the intestinal dysbiosis.

It should be noteworthy that discordances have been reported in the detection of microbiota alterations among patients with constipation. This discrepancy may be the result of different methods used for bacterial quantifications, the use of single samples and other factors (e.g. diet and phenotypic characterization of patients) (Simren et al. 2013). Furthermore, most studies assessed the fecal microbiota, which are readily accessible, but do not fully replicate profiles of the mucosal microbiota of the patients with constipation. The mucosal microbiota might affect epithelial and mucosal function to a greater degree than the fecal microbiota (Durban et al. 2012; Parkes et al. 2012). One recent study reported that the overall composition of the colonic mucosal microbiota was associated with constipation and genera from $\mathrm{Bac}$ teroidetes were more abundant in the colonic mucosal microbiota of patients with constipation. Meanwhile, the profile of the fecal microbiota was associated with colonic transit and methane production, but not constipation (Parthasarathy et al. 2016). More studies detailing higher resolution of the mucosal and fecal microbiota composition might expand our understanding of the relationships between intestinal microbiota and constipation.

Though widely used, the above cultural and/or molecular approaches could not assess the functional imbalance of intestinal microbiota in patients with constipation. Thereby, the function-based approach, based on the detection of specific metabolic activity expressed by a group of bacterial species, has been put forward in recent studies. Chassard et al. showed that the IBS-C microbiota was characterized by a high number of lactateand $\mathrm{H}_{2}$-utilising sulphate-reducing bacteria compared with healthy controls, which could in turn influence colonic motility and visceral sensitivity and generate IBS symptoms (Chassard et al. 2012). Due to changes in metabolism output, the functional dysbiosis might have important clinical implications and provide a new dimension in management of chronic constipation.

\section{Possible role of the intestinal microbiota in gut motility}

Most of our knowledge on the effect of intestinal microbiota on gut motility derives from studies in germ-free animals. Germ-free rats exhibited longer migrating myoelectric complex (MMC) intervals compared with conventional rats (Caenepeel et al. 1989). Further, the cecum of germ-free rats was enlarged and gastric emptying and colonic transit were delayed (Abrams 1977). Studies colonizing of conventional intestinal microbiota to germ-free rats revealed that Lactobacillus acidophilus and Bifidobacterium bifidum could reduce the MMC period and accelerate small intestinal transit, while Micrococcus luteus and Escherichia coli showed an inhibitory effect (Husebye et al. 2001). Barbara et al. put forward three mechanisms responsible for the effects of microbiota on intestinal motility (Barbara et al. 2005): (1) the release of bacterial substances or end-products of bacterial fermentation; (2) intestinal neuroendocrine factors; (3) mediators released by the gut immune response.

The bacterial endotoxin lipopolysaccharide may influence intestinal motility by delaying gastric emptying and inducing sphincteric dysfunction (Fan et al. 2001). Deconjugated bile salts, a kind of bacterial metabolite, may promote colonic motor responses and induce bile salt related diarrhea (Floch 2002). Short-chain fatty acids (SCFAs), such as butyrate, acetate, and propionate are produced in the colon by anaerobic bacterial metabolism of carbohydrates. SCFAs have been shown to stimulate ileal propulsive contractions by evoking prolonged propagated contractions and discrete clustered contractions. The possible mechanisms of SCFAs in gut motility may involve the intestinal release of 5-hydroxytryptamine (5-HT). In addition, SCFAs could directly stimulate the 
ileal and colonic smooth muscle contractility. Lactate can be quickly metabolized by specific bacterial species into butyrate or propionate. High concentration of butyrate may inhibit mucin secretion by intestinal goblet cells (Baxter et al. 2014). Further study indicates that butyrate may reduce stool volume by stimulating water and electrolyte absorption in the colon (Canani et al. 2011). The number of these lactate-utilising bacteria is obviously decreased tenfold in the faecal microbiota of IBS-C patients (Rajilic-Stojanovic et al. 2011). Human colonic gases produced by microflora may also be associated with changes in gut motility. For example, breath methane excretion in patients with slow-transit constipation was greater than in healthy subjects or patients with normal-transit constipation, supporting the idea that methane can slow gut transit (Attaluri et al. 2010). However, recent study reported that methane production was associated with the composition of the fecal microbiota, but not with constipation or colonic transit (Parthasarathy et al. 2016). Meanwhile, $\mathrm{H}_{2}$ accumulation has been postulated to account for the symptom of bloating and pain (Pimentel et al. 2000). Colonic $\mathrm{H}_{2} \mathrm{~S}$ has been demonstrated to modulate peripheral pain-related signals, which may ultimately influence gut sensory-motor functions (Kawabata et al. 2007). Cell-envelope-associated multi-protein system, termed as "starch utilization system (SUS)", is present in Bacteroides species such as Bacteroides thetaiotaomicron (Lammerts van Bueren et al. 2015). Increased number of Bacteroides species may be associated with production of organic acids in excess via fermentation, which may contribute to the symptoms of abdominal distension. Small intestinal bacterial overgrowth (SIBO) is a condition involves abnormal growth of endogenous bacteria in the small intestine resembling those normally found in the colon. The clinical manifestations of SIBO are wide ranging and include abdominal discomfort, bloating, diarrhea, weight loss and nutritional deficiencies (Gabrielli et al. 2013). Due to the inherent difficulties in measuring small bowel motility, few studies have illustrated a direct relationship between impaired small intestinal motility and SIBO. Roland et al. (2015) recently reported that patients undergoing wireless motility capsule with SIBO have significant delays in small bowel transit time as compared with those without. Future prospective studies are needed to further characterize SIBO and contributing pathophysiological mechanisms in small bowel dysmotility.

It has been hypothesized that intestinal microbiota could modulate gut motility through the release of neuroendocrine factors. For instance, the presence of somatostatin was firstly clarified in Bacillus subtilis (Lenard 1992). Germfree rats had increased gastrin-, serotonin-, and motilin-immunoreactive cells in selective areas of the gastrointestinal mucosa. Neuropeptide Y, an inhibitory neuropeptide, was found decreased in blood concentration after introduction of conventional intestinal microbiota in these rats (Husebye et al. 2001). These findings indirectly demonstrated that the intestinal microbiota could regulate endocrine cells and ultimately influence the gut motility. Besides, the effect of microbiota-derived SCFAs on colonic serotonin and motilin-containing enteroendocrine cells has also been proposed in the regulation of colonic physiology.

In immunocompetent hosts, the commensal colonic microbiota are major determinants of mucosal and systemic immunity. For example, Bacteroides fragilis can mediate the development of Foxp $3^{+}$Treg cells through the activation of Toll-like receptor (TLR)2 (Nutsch and Hsieh 2012). Clostridium species induce Foxp $3^{+}$Treg cells through the induction of transforming growth factor- $\beta$ (TGF- $\beta$ ) (Ivanov and Littman 2010). Mediators released by colonic immune cells are known to modulate various digestive functions. Increased expression of IL- $1 \beta$, IL- 6 and tumor necrosis factor $\alpha$ (TNF- $\alpha$ ) have been demonstrated in colitis rat model. IL- $1 \beta$ could cause a pronounced suppression of the synthesis and release of both acetylcholine and noradrenaline (Collins 1996). Synergistic interactions between IL- 1 and IL- 6 have been confirmed both pharmacologically and electrophysiologically (Atanasova et al. 2011). Similar observations were drawn with respect to the role of TNF- $\alpha$ to suppress noradrenaline release (O'Sullivan et al. 2009). Clostridial species and polysaccharide A derived from Bacteroidetes species strains induce IL-10 production and promote T-regulatory cell development (Suszko and ObminskaMrukowicz 2013). Segmented filamentous bacteria, Candidatus svagella, are required for differentiation of $\mathrm{T}$ helper 17 (TH17) cells and induce luminal secretion of IgA (Ivanov and Littman 2010). Disruptions in colonic immunity can result in abnormal responses to luminal contents and this mechanism is suspected to be a component in the development of colonic motility disorder.

\section{Possible microbiota-based therapy on chronic constipation \\ Dietary fibre}

Dietary fibre has been recommended on an empirical basis for the management of chronic constipation. As is known, dietary fibres can promote the excretion of intestinal mucin by stimulating the capacity of mucosal protein synthesis (Derrien et al. 2010). Dietary fibre is broken down in the proximal colon and provides an energy yielding substrate for microbial fermentation. The result of this is to stimulate the growth of intestinal microbiota and contribute significantly to the stool dry weight. Besides, fibres could promote the excretion of 
bacterial fermentation products, such as SCFAs, which has the pro-motility effects (Jennings et al. 2009). Dietary fibre is also an important source of gas in the colon. Hydrogen, methane and carbon dioxide, which are principal end products of bacterial fermentation, can increase stool bulk and promote colonic transit (Lopez Roman et al. 2008). There is evidence indicates that dietary fibres (wheat bran, pea fibres) can modulate intestinal microbiota, including the stimulation of beneficial bacterial species and the suppression of pathogenic bacterial species (Chen et al. 2013).

\section{Prebiotics}

Prebiotics are non-digestible substances that provide a beneficial physiological effect on the host by selectively stimulating the growth or activity of a limited number of favourable indigenous gut bacteria. Prebiotics stimulate the preferential growth of a limited number of healthpromoting commensal flora already residing in the colon, such as Lactobacilli and Bifidobacteria. Examples of prebiotics include fructo-oligosaccharides, galactooligosaccharides and inulin. Fibre and fibre supplements employed in the treatment of constipation also exert prebiotic effects (Bouhnik et al. 2004). Prebiotics are subjected to bacterial metabolism in the colon, where they are transformed to lactic and short-chain carboxylic acids. It has been demonstrated that galacto-oligosaccharides seemed to promote the intestinal peristalsis and relieve constipation ( $\mathrm{Li}$ et al. 2013). The consumption of inulin-type fructans affects intestinal microbiota and stimulates bowel movements normalizing stool frequency in constipated patients (Quigley 2011). It should be noteworthy that most of the evidence regarding the beneficial effect of prebiotics in constipation is derived from animal studies. Human trials are only conducted on small number of constipated subjects (Table 1). However, one recent trial of prebiotics in sixty constipated women reported that there was no significant difference in satisfaction in relief of constipation between prebiotic group and placebo group (Linetzky Waitzberg et al. 2012). Further adequately powered studies need to be carried out to draw more definitive conclusions.

\section{Probiotics}

Probiotics are live or attenuated microorganisms defined as being capable of conferring health benefits on their host when they are given in sufficient quantities and administered continuously, beyond any inherent nutritional value. Probiotics have demonstrated beneficial effects in patients with constipation, making them increasingly used as alterative treatment options (Table 2). A recent systematic review of probiotics for the treatment of chronic constipation demonstrated that probiotics did lead to a significant improvement in the mean number of stools per week (Dimidi et al. 2014). Several mechanisms have been proposed by which probiotics may benefit chronic constipation: (1) probiotics may modify the altered intestinal microbiota in patients with constipation; (2) probiotic metabolites may alter gut sensation and motility function (Waller et al. 2011); (3) some probiotics may regulate the intraluminal environment, such as increasing the end products of bacterial fermentation, reducing luminal $\mathrm{pH}$ (Waller et al. 2011), etc.

Bifidobacteria and Lactobacilli are the generally recognized beneficial species with various health-promoting functions such as the production of SCFAs, stimulation of intestinal peristalsis and increasing the humidity of the fecal bolus (Ojetti et al. 2014). A large randomized controlled trial demonstrated that the intake of an effective amount of Lactobacillus plantarum and Bifidobacterium breve, or Bifidobacterium lactis is able to significantly relieve the evacuation disorders and hard stools in patients with constipation (Del Piano et al. 2010). The supplementation with Lactobacillus casei

Table 1 Summary of randomized controlled trials of prebiotics for the management of chronic constipation

\begin{tabular}{|c|c|c|c|c|}
\hline References & Subjects & Intervention & Comparator & Author's conclusion \\
\hline Linetzky Waitzberg et al. (2012) & $\begin{array}{l}\text { Patients } n=60 \text { (control } \\
\begin{array}{l}n=32, \text { Intervention } \\
n=28)\end{array}\end{array}$ & Inulin & Placebo & $\begin{array}{l}\text { Decrease the amount of } \\
\text { pathological bacteria of the } \\
\text { Clostridium genera }\end{array}$ \\
\hline Bouhnik et al. (2004) & $\begin{array}{l}\text { Patients } n=65 \text { (control } \\
\begin{array}{l}n=32, \text { Intervention } \\
n=33 \text { ) }\end{array}\end{array}$ & Lactulose & Polyethylene glycol & $\begin{array}{l}\text { Beneficial effects, an increase in } \\
\text { faecal bifidobacteria counts }\end{array}$ \\
\hline Li et al. (2013) & Mice $n=40$ & $\begin{array}{l}\text { Deshipu stachyose granules } \\
\text { (DSG) }\end{array}$ & Placebo & $\begin{array}{l}\text { Facilitating intestinal peristalsis } \\
\text { and fecal excretion, increasing } \\
\text { beneficial intestinal bacteria } \\
\text { and inhibiting pathogenic } \\
\text { bacteria }\end{array}$ \\
\hline Li et al. (2011) & Rats $\mathrm{n}=90$ & $\begin{array}{c}\text { Prebiotics (a combination of } \\
\text { GOS, XOS, OF and inulin) }\end{array}$ & Placebo & $\begin{array}{l}\text { Beneficial effects on constipa- } \\
\text { tion }\end{array}$ \\
\hline
\end{tabular}


Table 2 Summary of randomized controlled trials of probiotics for the management of chronic constipation

\begin{tabular}{|c|c|c|c|c|}
\hline References & Population & Intervention & Comparator & Author's conclusion \\
\hline Tabbers et al. (2011) & $\begin{array}{l}n=159(\text { control } n=80 \\
\text { intervention } n=79)\end{array}$ & B. lactis DN-173010 & Acidified milk without probiotics & $\begin{array}{l}\text { Increased stool frequency, but not } \\
\text { statistically significant compared } \\
\text { with control group }\end{array}$ \\
\hline Coccorullo et al. (2010) & $\begin{array}{c}n=44 \text { (control } n=22 \\
\text { intervention } n=22)\end{array}$ & L. reuteri DSM 17938 & Identical placebo & Increased bowel frequency \\
\hline Favretto et al. (2013) & $\begin{array}{l}n=30(\text { control } n=15 \\
\text { intervention } n=15)\end{array}$ & B. lactis $\mathrm{Bi}-07$ & Fresh cheese without probiotics & Beneficial effects \\
\hline Yang et al. (2008) & $\begin{array}{l}n=126(\text { control } n=63 \\
\text { intervention } n=63)\end{array}$ & B. lactis DN-173010 & Acidified milk without probiotics & $\begin{array}{l}\text { Beneficial effects on stool fre- } \\
\text { quency, defecation condition } \\
\text { and stool consistency }\end{array}$ \\
\hline Ishizuka et al. (2012) & $\mathrm{n}=17$ (cross-over design) & B. lactis GCL2505 & Milk-like drink & Beneficial effects \\
\hline Waller et al. (2011) & $\begin{array}{l}n=100 \text { (control } n=34 \\
\text { Intervention: high dose } \\
n=33 \text { low dose } n=33 \text { ) }\end{array}$ & B. lactis HN019 & Capsules with rice maltodextrin & $\begin{array}{l}\text { Decreased whole gut transit time } \\
\text { in a dose-dependent manner }\end{array}$ \\
\hline Mazlyn et al. (2013) & $\begin{array}{c}n=90 \text { (control } n=43 \\
\text { intervention } n=47)\end{array}$ & L. casei Shirota & $\begin{array}{l}\text { Fermented milk without probiot- } \\
\text { ics }\end{array}$ & $\begin{array}{l}\text { Improvement in constipation } \\
\text { severity }\end{array}$ \\
\hline Riezzo et al. (2012) & $\mathrm{n}=20$ (cross-over design) & L. paracasei IMPC 2.1 & Artichokes without probiotics & Beneficial effects \\
\hline Koebnick et al. (2003) & $\begin{array}{l}n=70(\text { control } n=35 \\
\text { intervention } n=35)\end{array}$ & L. casei shirota & Beverage without probiotics & $\begin{array}{l}\text { Beneficial effects on self-reported } \\
\text { severity of constipation and } \\
\text { stool consistency }\end{array}$ \\
\hline
\end{tabular}

Shirota could significantly increase the frequency of defecations and the softness of the stool in IBS-C patients (Koebnick et al. 2003). A positive effect of Lactobacillus reuteri on bowel movement frequency has been confirmed in both adult and children patients with constipation (Wu et al. 2013). Evidence showed L. reuteri could promote both the frequency and velocity of colonic myoelectric motility complex (Barbara et al. 2005). One in vitro study indicated that Escherichia coli Nissle 1917 supernatants could enhance colonic contractility by direct stimulation of smooth muscle cells (Bar et al. 2009).

Some probiotics, such as Bifidobacterium lactis DN-173010 and Bifidobacterium longum could modify the metabolic activities of the colonic microbiota and improve lactose digestion in Chinese lactose-intolerant subjects (He et al. 2008). In children, Lactobacillus casei rhamnosus Lcr35 showed a favorable effect on relieving the symptoms of constipation (Bu et al. 2007). The combination of probiotics and prebiotics, which is named synbiotics, may provide synergistic effects. Synbiotic administration may improve the survival of probiotics and restore intestinal microbial balance, which may have positive effects on the treatment of constipation (Khodadad and Sabbaghian 2010). A meta-analysis conducted by Alexander C. Ford reported that synbiotics appeared to be more effective than placebo in chronic constipation. And the number needed to treat (NNT) with synbiotics in chronic constipation was 5 (95\% CI 3-14) (Ford et al. 2014).
Probiotics have been widely used nowadays for the treatment of constipation, however, concerns about the safety of probiotics still warrant further discussion. Probiotic administration may modulate the composition of the intestinal microbiota and consequently induce the alteration of metabolic activities and colonic immunological activities (Dai et al. 2014). Besides, the probiotic administration may transfer the antimicrobial resistance genes to the normal intestinal flora and pathogenic species (Drago et al. 2013).

\section{Fecal microbiota transplantation}

Fecal microbiota transplantation (FMT), also known as "fecal bacteriotherapy" or "fecal infusion", refers to the process of transplanting the functional flora from the stools of healthy donor to the gastrointestinal tract of recipient individual. It has been proposed as a therapeutic approach for chronic constipation by reestablishment of the wide diversity of intestinal flora. For example, one patient reported by Andrews et al. developed constipation and received FMT therapy. Two to three days following therapy, the patient's stool frequency increased to 1-2 per day without laxative-use (Borody et al. 2004). Borody et al. administered FMT to 4 patients with chronic constipation. All 4 patients experienced immediate resolution of symptoms of constipation to 1-2 stools per day with an accompanying resolution of most associated symptoms such as episodic nausea, vomiting, bloating and abdominal pain. And this improvement persisted for 6-28 months of follow-up (Borody et al. 1989). Li et al. treated 24 patients with slow 
transit constipation (STC) by means of FMT. The patients' stool frequency increased from a mean of 1.8 (SD 1.3) per week to 4.1 (SD 2.6) at week 12 post-FMT. Compared with baseline, significant overall improvements were seen in gastrointestinal quality-of-life index score during 12 weeks of follow-up (Tian et al. 2016). Though published reports on FMT are few in number and consist of just small uncontrolled open studies and case reports, the therapeutic benefits of FMT for the treatment of constipation suggests potential for this inexpensive and safe treatment modality to undergo further investigations for clinical use.

\section{Conclusions}

Collectively, the altered intestinal microbiota may play an essential role in the pathogenesis of chronic constipation. However, the precise mechanism of intestinal microbiota on the regulation of gut sensory and motor functions is still partly unclear. Future research identifying precisely how the intestinal microbiota participate in the modulation of gut physiology and pathophysiology will be beneficial for our understanding of the interactions between the intestinal microbiota and gut function, which is also invaluable in ultimately developing new therapeutic tools for the management of chronic constipation.

\section{Abbreviations}

SCFAs: short-chain fatty acids; IBS-C: constipation predominant-irritable bowel syndrome; MMC: migrating myoelectric complex; 5-HT: 5-hydroxytryptamine; SUS: starch utilization system; SIBO: small intestinal bacterial overgrowth; TGF- $\beta$ : transforming growth factor- $\beta$; TNF- $\alpha$ : tumor necrosis factor $\alpha$; FMT: fecal microbiota transplantation; STC: slow transit constipation.

\section{Authors' contributions}

YZ wrote the paper. Y-B Y conceived, revised the manuscript and gave the final approval. Both authors read and approved the final manuscript.

\section{Author details}

${ }^{1}$ Department of Geriatrics, Jinan Military General Hospital, Jinan 250031, People's Republic of China. ${ }^{2}$ Department of Gastroenterology, Qilu Hospital, Shandong University, Jinan 250012, People's Republic of China.

\section{Acknowledgements}

This work was supported by the National Natural Science Foundation of China (NSFC, 81200270) and the scientific research foundation for outstanding young scientist of Shandong Province (BS2012SW012).

\section{Competing interests}

The authors declare that they have no competing interests.

Received: 8 April 2016 Accepted: 12 July 2016

Published online: 19 July 2016

\section{References}

Abrams GD (1977) Microbial effects on mucosal structure and function. Am J Clin Nutr 30(11):1880-1886

Atanasova K, Van Gucht S, Barbe F, Duchateau L, Van Reeth K (2011) Lipoteichoic acid from Staphylococcus aureus exacerbates respiratory disease in porcine respiratory coronavirus-infected pigs. Vet J 188(2):210-215
Attaluri A, Jackson M, Valestin J, Rao SS (2010) Methanogenic flora is associated with altered colonic transit but not stool characteristics in constipation without IBS. Am J Gastroenterol 105(6):1407-1411

Bar F, Von Koschitzky H, Roblick U, Bruch HP, Schulze L, Sonnenborn U, Bottner M, Wedel T (2009) Cell-free supernatants of Escherichia coli Nissle 1917 modulate human colonic motility: evidence from an in vitro organ bath study. Neurogastroenterol Motil 21 (5):559-566, e516-557

Barbara G, Stanghellini V, Brandi G, Cremon C, Di Nardo G, De Giorgio R, Corinaldesi R (2005) Interactions between commensal bacteria and gut sensorimotor function in health and disease. Am J Gastroenterol 100(11):2560-2568

Baxter NT, Zackular JP, Chen GY, Schloss PD (2014) Structure of the gut microbiome following colonization with human feces determines colonic tumor burden. Microbiome 2:20

Bharucha AE (2007) Constipation. Best Pract Res Clin Gastroenterol 21(4):709-731

Blaser M, Bork P, Fraser C, Knight R, Wang J (2013) The microbiome explored: recent insights and future challenges. Nat Rev Microbiol 11(3):213-217

Borody TJ, George L, Andrews P, Brandl S, Noonan S, Cole P, Hyland L, Morgan A, Maysey J, Moore-Jones D (1989) Bowel-flora alteration: a potential cure for inflammatory bowel disease and irritable bowel syndrome? Med J Aust 150(10):604

Borody TJ, Warren EF, Leis SM, Surace R, Ashman O, Siarakas S (2004) Bacteriotherapy using fecal flora: toying with human motions. J Clin Gastroenterol 38(6):475-483

Bouhnik Y, Neut C, Raskine L, Michel C, Riottot M, Andrieux C, Guillemot F, Dyard F, Flourie B (2004) Prospective, randomized, parallel-group trial to evaluate the effects of lactulose and polyethylene glycol-4000 on colonic flora in chronic idiopathic constipation. Aliment Pharmacol Ther 19(8):889-899

Bu LN, Chang MH, Ni YH, Chen HL, Cheng CC (2007) Lactobacillus casei rhamnosus Lcr35 in children with chronic constipation. Pediatr Int 49(4):485-490

Caenepeel P, Janssens J, Vantrappen G, Eyssen H, Coremans G (1989) Interdigestive myoelectric complex in germ-free rats. Dig Dis Sci 34(8):1180-1184

Canani RB, Costanzo MD, Leone L, Pedata M, Meli R, Calignano A (2011) Potential beneficial effects of butyrate in intestinal and extraintestinal diseases. World J Gastroenterol 17(12):1519-1528

Chassard C, Dapoigny M, Scott KP, Crouzet L, Del'homme C, Marquet P, Martin JC, Pickering G, Ardid D, Eschalier A, Dubray C, Flint HJ, Bernalier-Donadille A (2012) Functional dysbiosis within the gut microbiota of patients with constipated-irritable bowel syndrome. Aliment Pharmacol Ther 35(7):828-838

Chen H, Mao X, He J, Yu B, Huang Z, Yu J, Zheng P, Chen D (2013) Dietary fibre affects intestinal mucosal barrier function and regulates intestinal bacteria in weaning piglets. Br J Nutr 110(10):1837-1848

Coccorullo P, Strisciuglio C, Martinelli M, Miele E, Greco L, Staiano A (2010) Lactobacillus reuteri (DSM 17938) in infants with functional chronic constipation: a double-blind, randomized, placebo-controlled study. J Pediatr 157(4):598-602

Collins SM (1996) The immunomodulation of enteric neuromuscular function: implications for motility and inflammatory disorders. Gastroenterology 111(6):1683-1699

Dai C, Jiang M, Sun MJ (2014) The safety of probiotics in IBS and CIC is worthy of further discussion. Am J Gastroenterol 109(11):1838-1839

Del Piano M, Carmagnola S, Anderloni A, Andorno S, Ballare M, Balzarini M, Montino F, Orsello M, Pagliarulo M, Sartori M, Tari R, Sforza F, Capurso L (2010) The use of probiotics in healthy volunteers with evacuation disorders and hard stools: a double-blind, randomized, placebo-controlled study. J Clin Gastroenterol 44(Suppl 1):S30-S34

Derrien M, van Passel MW, van de Bovenkamp JH, Schipper RG, de Vos WM, Dekker J (2010) Mucin-bacterial interactions in the human oral cavity and digestive tract. Gut Microbes 1(4):254-268

Dimidi E, Christodoulides S, Fragkos KC, Scott SM, Whelan K (2014) The effect of probiotics on functional constipation in adults: a systematic review and meta-analysis of randomized controlled trials. Am J Clin Nutr 100(4):1075-1084

Drago L, Mattina R, De Vecchi E, Toscano M (2013) Phenotypic and genotypic antibiotic resistance in some probiotics proposed for medical use. Int J Antimicrob Agents 41(4):396-397 
Durban A, Abellan JJ, Jimenez-Hernandez N, Salgado P, Ponce M, Ponce J, Garrigues V, Latorre A, Moya A (2012) Structural alterations of faecal and mucosa-associated bacterial communities in irritable bowel syndrome. Environ Microbiol Rep 4(2):242-247

Fan YP, Chakder S, Gao F, Rattan S (2001) Inducible and neuronal nitric oxide synthase involvement in lipopolysaccharide-induced sphincteric dysfunction. Am J Physiol Gastrointest Liver Physiol 280(1):G32-G42

Favretto DC, Pontin B, Moreira TR (2013) Effect of the consumption of a cheese enriched with probiotic organisms (Bifidobacterium lactis bi-07) in improving symptoms of constipation. Arq Gastroenterol 50(3):196-201

Floch MH (2002) Bile salts, intestinal microflora and enterohepatic circulation. Dig Liver Dis 34(Suppl 2):S54-S57

Ford AC, Quigley EM, Lacy BE, Lembo AJ, Saito YA, Schiller LR, Soffer EE, Spiege BM, Moayyedi P (2014) Efficacy of prebiotics, probiotics, and synbiotics in irritable bowel syndrome and chronic idiopathic constipation: systematic review and meta-analysis. Am J Gastroenterol 109(10):1547-1561; quiz 1546,1562

Gabrielli M, D'Angelo G, Di Rienzo T, Scarpellini E, Ojetti V (2013) Diagnosis of small intestinal bacterial overgrowth in the clinical practice. Eur Rev Med Pharmacol Sci 17(Suppl 2):30-35

Gerritsen J, Smidt H, Rijkers GT, de Vos WM (2011) Intestinal microbiota in human health and disease: the impact of probiotics. Genes Nutr 6(3):209-240

He T, Priebe MG, Zhong Y, Huang C, Harmsen HJ, Raangs GC, Antoine JM, Welling GW, Vonk RJ (2008) Effects of yogurt and bifidobacteria supplementation on the colonic microbiota in lactose-intolerant subjects. J Appl Microbiol 104(2):595-604

Husebye E, Hellstrom PM, Sundler F, Chen J, Midtvedt T (2001) Influence of microbial species on small intestinal myoelectric activity and transit in germ-free rats. Am J Physiol Gastrointest Liver Physiol 280(3):G368-G380

Ishizuka A, Tomizuka K, Aoki R, Nishijima T, Saito Y, Inoue R, Ushida K, Mawatari T, Ikeda T (2012) Effects of administration of Bifidobacterium animalis subsp. lactis GCL2505 on defecation frequency and bifidobacterial microbiota composition in humans. J Biosci Bioeng 113(5):587-591

Ivanov II, Littman DR (2010) Segmented filamentous bacteria take the stage. Mucosal Immunol 3(3):209-212

Jennings A, Davies GJ, Costarelli V, Dettmar PW (2009) Dietary fibre, fluids and physical activity in relation to constipation symptoms in pre-adolescent children. J Child Health Care 13(2):116-127

Kawabata A, Ishiki T, Nagasawa K, Yoshida S, Maeda Y, Takahashi T, Sekiguchi F Wada T, Ichida S, Nishikawa H (2007) Hydrogen sulfide as a novel nociceptive messenger. Pain 132(1-2):74-81

Khalif IL, Quigley EM, Konovitch EA, Maximova ID (2005) Alterations in the colonic flora and intestinal permeability and evidence of immune activation in chronic constipation. Dig Liver Dis 37(11):838-849

Khodadad A, Sabbaghian M (2010) Role of synbiotics in the treatment of childhood constipation: a double-blind randomized placebo controlled trial. Iran J Pediatr 20(4):387-392

Kirgizov IV, Sukhorukov AM, Dudarev VA, Istomin AA (2001) Hemostasis in children with dysbacteriosis in chronic constipation. Clin Appl Thromb Hemost 7(4):335-338

Koebnick C, Wagner I, Leitzmann P, Stern U, Zunft HJ (2003) Probiotic beverage containing Lactobacillus casei Shirota improves gastrointestinal symptoms in patients with chronic constipation. Can J Gastroenterol 17(11):655-659

Lammerts van Bueren A, Saraf A, Martens EC, Dijkhuizen L (2015) Differential metabolism of exopolysaccharides from probiotic Lactobacilli by the human gut symbiont Bacteroides thetaiotaomicron. Appl Environ Microbiol 81(12):3973-3983

Lenard J (1992) Mammalian hormones in microbial cells. Trends Biochem Sci 17(4):147-150

Li Y, Zong Y, Qi J, Liu K (2011) Prebiotics and oxidative stress in constipated rats. J Pediatr Gastroenterol Nutr 53(4):447-452

Li T, Lu X, Yang X (2013) Stachyose-enriched alpha-galacto-oligosaccharides regulate gut microbiota and relieve constipation in mice. J Agric Food Chem 61(48):11825-11831

Linetzky Waitzberg D, Alves Pereira CC, Logullo L, Manzoni Jacintho T, Almeida D, Teixeira da Silva ML, de Miranda Matos, Torrinhas RS (2012) Microbiota benefits after inulin and partially hydrolized guar gum supplementation: a randomized clinical trial in constipated women. Nutr Hosp 27(1):123-129
Lopez Roman J, Martinez Gonzalvez AB, Luque A, Pons Minano JA, Vargas Acosta A, Iglesias JR, Hernandez M, Villegas JA (2008) The effect of a fibre enriched dietary milk product in chronic primary idiopatic constipation. Nutr Hosp 23(1):12-19

Mazlyn MM, Nagarajah LH, Fatimah A, Norimah AK, Goh KL (2013) Effects of a probiotic fermented milk on functional constipation: a randomized, double-blind, placebo-controlled study. J Gastroenterol Hepatol 28(7):1141-1147

Nourrisson C, Scanzi J, Pereira B, NkoudMongo C, Wawrzyniak I, Cian A, Viscogliosi E, Livrelli V, Delbac F, Dapoigny M, Poirier P (2014) Blastocystis is associated with decrease of fecal microbiota protective bacteria: comparative analysis between patients with irritable bowel syndrome and control subjects. PLOS ONE 9(11):e111868

Nutsch KM, Hsieh CS (2012) T cell tolerance and immunity to commensal bacteria. Curr Opin Immunol 24(4):385-391

Ojetti V, laniro G, Tortora A, D'Angelo G, Di Rienzo TA, Bibbo S, Migneco A, Gasbarrini A (2014) The effect of Lactobacillus reuteri supplementation in adults with chronic functional constipation: a randomized, double-blind, placebo-controlled trial. J Gastrointestin Liver Dis 23(4):387-391

O'Sullivan JB, Ryan KM, Curtin NM, Harkin A, Connor TJ (2009) Noradrenaline reuptake inhibitors limit neuroinflammation in rat cortex following a systemic inflammatory challenge: implications for depression and neurodegeneration. Int J Neuropsychopharmacol 12(5):687-699

Parkes GC, Rayment NB, Hudspith BN, Petrovska L, Lomer MC, Brostoff J, Whelan K, Sanderson JD (2012) Distinct microbial populations exist in the mucosa-associated microbiota of sub-groups of irritable bowel syndrome. Neurogastroenterol Motil 24(1):31-39

Parthasarathy G, Chen J, Chen X, Chia N, O'Connor HM, Wolf PG, Gaskins HR, Bharucha AE (2016) Relationship between microbiota of the colonic mucosa vs feces and symptoms, colonic transit, and methane production in female patients with chronic constipation. Gastroenterology 150(2):367 e361-379 e361

Pimentel M. Chow EJ, Lin HC (2000) Eradication of small intestinal bacterial overgrowth reduces symptoms of irritable bowel syndrome. Am J Gastroenterol 95(12):3503-3506

Pryde SE, Duncan SH, Hold GL, Stewart CS, Flint HJ (2002) The microbiology of butyrate formation in the human colon. FEMS Microbiol Lett 217(2):133-139

Quigley EM (2011) The enteric microbiota in the pathogenesis and management of constipation. Best Pract Res Clin Gastroenterol 25(1):119-126

Rajilic-Stojanovic M, Biagi E, Heilig HG, Kajander K, Kekkonen RA, Tims S, de Vos WM (2011) Global and deep molecular analysis of microbiota signatures in fecal samples from patients with irritable bowel syndrome. Gastroenterology 141(5):1792-1801

Riezzo G, Orlando A, D'Attoma B, Guerra V, Valerio F, Lavermicocca P, De Candia S, Russo F (2012) Randomised clinical trial: efficacy of Lactobacillus paracasei-enriched artichokes in the treatment of patients with functional constipation-a double-blind, controlled, crossover study. Aliment Pharmacol Ther 35(4):441-450

Roland BC, Ciarleglio MM, Clarke JO, Semler JR, Tomakin E, Mullin GE, Pasricha PJ (2015) Small intestinal transit time is delayed in small intestinal bacterial overgrowth. J Clin Gastroenterol 49(7):571-576

Simren M, Barbara G, Flint HJ, Spiegel BM, Spiller RC, Vanner S, Verdu EF, Whorwell PJ, Zoetendal EG (2013) Intestinal microbiota in functional bowel disorders: a Rome foundation report. Gut 62(1):159-176

Sokol H, Pigneur B, Watterlot L, Lakhdari O, Bermudez-Humaran LG, Gratadoux JJ, Blugeon S, Bridonneau C, Furet JP, Corthier G, Grangette C, Vasquez N, Pochart P, Trugnan G, Thomas G, Blottiere HM, Dore J, Marteau P, Seksik P, Langella P (2008) Faecalibacterium prausnitzii is an anti-inflammatory commensal bacterium identified by gut microbiota analysis of Crohn disease patients. Proc Natl Acad Sci USA 105(43):16731-16736

Suszko A, Obminska-Mrukowicz B (2013) Influence of polysaccharide fractions isolated from Caltha palustris $\mathrm{L}$. on the cellular immune response in collagen-induced arthritis (CIA) in mice. A comparison with methotrexate. J Ethnopharmacol 145(1):109-117

Tabbers MM, Chmielewska A, Roseboom MG, Crastes N, Perrin C, Reitsma JB, Norbruis O, Szajewska H, Benninga MA (2011) Fermented milk containing Bifidobacterium lactis DN-173 010 in childhood constipation: a randomized, double-blind, controlled trial. Pediatrics 127(6):e1392-e1399 
Tian H, Ding C, Gong J, Ge X, McFarland LV, Gu L, Wei Y, Chen Q, Zhu W, Li J, Li N (2016) Treatment of slow transit constipation with fecal microbiota transplantation: a pilot study. J Clin Gastroenterol. doi:10.1097/ MCG.0000000000000472

Waller PA, Gopal PK, Leyer GJ, Ouwehand AC, Reifer C, Stewart ME, Miller LE (2011) Dose-response effect of Bifidobacterium lactis HNO19 on whole gut transit time and functional gastrointestinal symptoms in adults. Scand J Gastroenterol 46(9):1057-1064

Wu RY, Pasyk M, Wang B, Forsythe P, Bienenstock J, Mao YK, Sharma P, Stanisz AM, Kunze WA (2013) Spatiotemporal maps reveal regional differences in the effects on gut motility for Lactobacillus reuteri and rhamnosus strains. Neurogastroenterol Motil 25(3):e205-e214

Yang YX, He M, Hu G, Wei J, Pages P, Yang XH, Bourdu-Naturel S (2008) Effect of a fermented milk containing Bifidobacterium lactis DN-173010 on Chinese constipated women. World J Gastroenterol 14(40):6237-6243

Zhu L, Liu W, Alkhouri R, Baker RD, Bard JE, Quigley EM, Baker SS (2014) Structural changes in the gut microbiome of constipated patients. Physiol Genomics 46(18):679-686

Zoppi G, Cinquetti M, Luciano A, Benini A, Muner A, Bertazzoni Minelli E (1998) The intestinal ecosystem in chronic functional constipation. Acta Paediatr 87(8):836-841

\section{Submit your manuscript to a SpringerOpen ${ }^{\circ}$ journal and benefit from:}

- Convenient online submission

- Rigorous peer review

- Immediate publication on acceptance

- Open access: articles freely available online

- High visibility within the field

- Retaining the copyright to your article 